\title{
Catalytic Reduction of Dinitrogen into Ammonia and Hydrazine Us- ing Chromium Complexes Bearing PCP-Type Pincer Ligand
}

\author{
Yuya Ashida ${ }^{\dagger}$ Akihito Egi, ${ }^{\star}$ Kazuya Arashiba ${ }^{\dagger}$ Hiromasa Tanaka,$^{\S}$ Shogo Kuriyama,${ }^{\dagger}$ Kazunari Yoshi- \\ zawa*, and Yoshiaki Nishibayashi*,† \\ †Department of Applied Chemistry, School of Engineering, The University of Tokyo, Hongo, Bunkyo-ku, Tokyo 113-8656, \\ Japan \\ Institute for Materials Chemistry and Engineering, Kyushu University, Nishi-ku, Fukuoka 819-0395, Japan \\ §School of Liberal Arts and Sciences, Daido University, Takiharu-cho, Minami-ku, Nagoya 457-8530, Japan
}

Supporting Information Placeholder

\begin{abstract}
A series of chromium-halide, -nitride, and -dinitrogen complexes bearing a carbene- and phosphine-based PCP-type pincer ligand is newly prepared and some of them are found to work as effective catalysts to reduce dinitrogen under atmospheric pressure, whereby up to 8.40 equiv of ammonia and 2.46 equiv of hydrazine ( 13.32 equiv of fixed $\mathrm{N}$ atom) are produced based on the chromium atom. To the best of our knowledge, this is the first successful example of chromiumcatalyzed conversion of dinitrogen to ammonia and hydrazine under mild reaction conditions.
\end{abstract}

Nitrogen is an essential element for living organisms although $78 \%$ of atmospheric air consists of dinitrogen gas, use of this gas as a nitrogen source in the synthesis of nitrogen-containing compounds is difficult, given the high stability of the nitrogen-nitrogen triple bond in dinitrogen. Therefore, the fixation of nitrogen from dinitrogen is one of the most interesting chemical reactions. Today, artificial nitrogen fixation is performed via the Haber-Bosch process, whereby ammonia is produced starting from dinitrogen and dihydrogen under harsh conditions, leading to much energy expenditure and substantial $\mathrm{CO}_{2}$ emissions. ${ }^{1}$ On the other hand, in nature, nitrogenase, an enzyme comprising molybdenum-iron multinuclear clusters as its active site, presides to a catalytic nitrogen fixation reaction occurring under ambient conditions. ${ }^{2}$ Therefore, transition metal complexes inspired by the active site of nitrogenase have been widely investigated with the goal of achieving artificial catalytic nitrogen fixation under mild reaction conditions. ${ }^{3,4}$ Various transition metal complexes containing molybdenum, ${ }^{5-7}$ iron, ${ }^{8-10}$ cobalt, 11 vanadium, ${ }^{12}$ titanium, ${ }^{13}$ ruthenium, ${ }^{14}$ osmium, ${ }^{14}$ and rhenium ${ }^{15}$ have been reported to catalyze nitrogen fixation to produce ammonia and/or hydrazine. Quite recently, we have found that $\mathrm{SmI}_{2}$ and simple alcohols or water used in combination acted as reductant and proton sources, respectively, to afford the high-performance formation of ammonia catalyzed by molybdenum trihalide complexes bearing pincer ligands under ambient conditions. ${ }^{6 \mathrm{~d}}$
Nitrogen fixation catalyzed by chromium complexes has also attracted much attention, because chromium is a group- 6 metal, much like molybdenum, which has displayed high catalytic activity in nitrogen fixation. ${ }^{5-7}$ However, in contrast to molybdenum complexes, only few examples exist of chromium complexes catalyzing nitrogen fixation. ${ }^{16-20}$ In 1972, Shiina reported the first chromium-catalyzed nitrogen fixation reaction, whereby $\mathrm{CrCl}_{3}$ catalyzed the conversion of dinitrogen to $\mathrm{N}\left(\mathrm{SiMe}_{3}\right)_{3}$ known as the equivalent of ammonia. ${ }^{17}$ After the publication of Shiina's report, no chromium-catalyzed nitrogen fixation reactions were reported until 2018, when Mock and co-workers reported the catalytic $\mathrm{N}\left(\mathrm{SiMe}_{3}\right)_{3}$ formation achieved using chromium-dinitrogen complexes as catalysts. ${ }^{19 a}$ Recently, Xi's ${ }^{19 b}$ and Murray's ${ }^{19 c}$ groups also reported that multinuclear chromium-dinitrogen complexes displayed catalytic activity in the formation of $\mathrm{N}\left(\mathrm{SiMe}_{3}\right)_{3}$. Although catalytic reduction of dinitrogen to $\mathrm{N}\left(\mathrm{SiMe}_{3}\right)_{3}$ using chromium complexes has been reported, examples whereby dinitrogen was reduced to ammonia have been limited only to stoichiometric reactions. ${ }^{19 a, 20}$

In the present study, we have achieved the chromium-catalyzed formation of ammonia and hydrazine from dinitrogen under mild reaction conditions. In this reaction course, chromium complexes bearing a phosphine- and carbene-based PCP-type pincer ligand $(\mathrm{PCP}=1,3$-bis((di-tert-butylphosphino)methyl)benzimidazol-2-ylidene) worked as efficient catalysts in the presence of $\mathrm{KC}_{8}$ acting as reductant and phosphonium salts as proton sources. To the best of our knowledge, this is the first reported example of the chromium-catalyzed conversion of dinitrogen at atmospheric pressure to ammonia.

First, we synthesized chromium complexes bearing the PCP-type pincer ligand, which proved the most effective ligand in the molybdenum-catalyzed conversion of dinitrogen to ammonia. ${ }^{6 \mathrm{~d}}$ The reaction of $\mathrm{CrCl}_{2}$ with the benzimidazolium salt of PCP in tetrahydrofuran (THF) at room temperature over the course of $20 \mathrm{~h}$ produced [ $\mathrm{CrCl}_{2}$ (PCP)] (1a) in 59\% yield (Scheme 1). We then transformed $1 \mathbf{a}$ into a range of different complexes. Ligand exchange in $\mathbf{1 a}$ in the presence of an excess amount of NaI proceeded smoothly to afford [ $\left.\mathrm{CrI}_{2}(\mathrm{PCP})\right]$ (1b) 


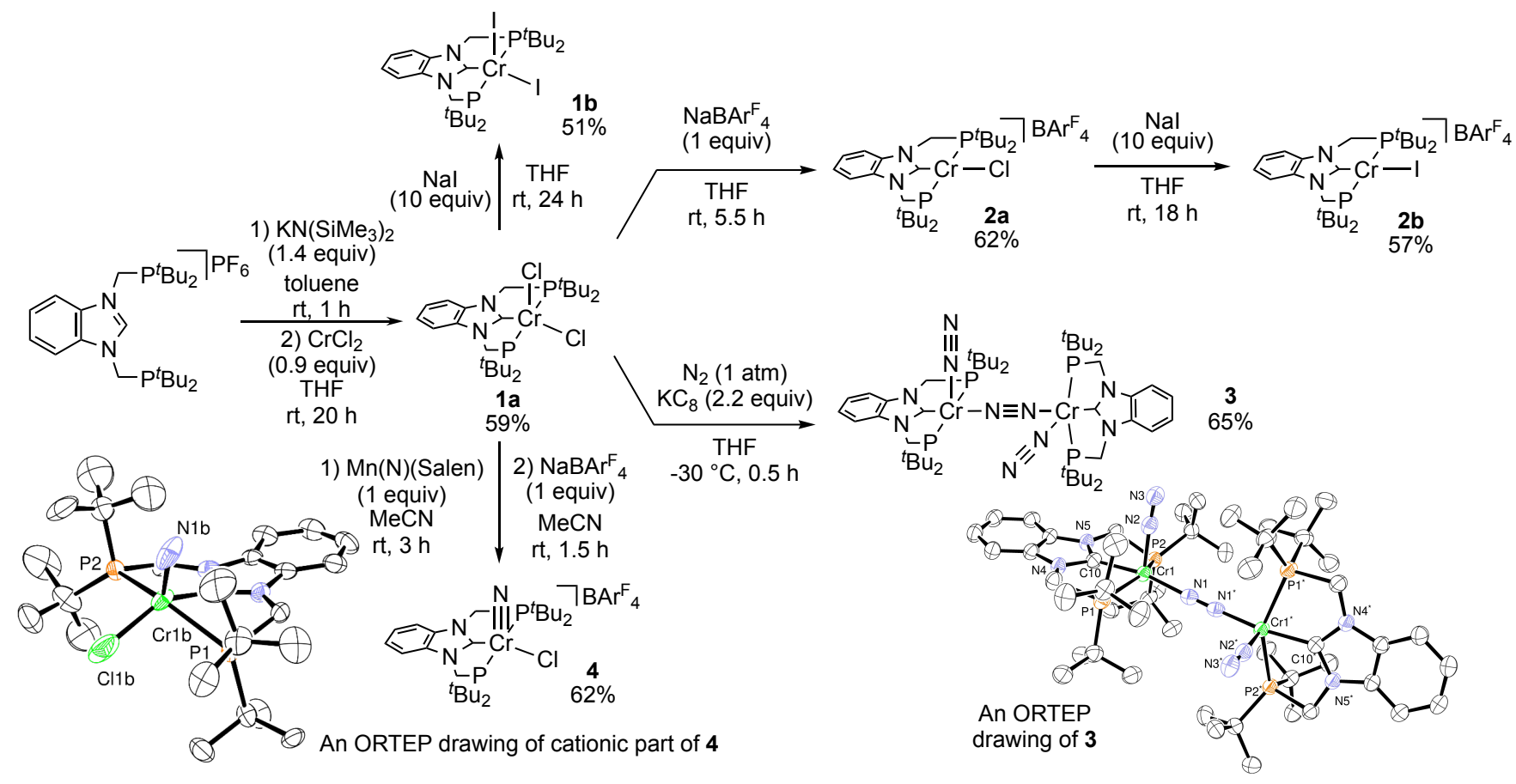

\section{Scheme 1. Synthesis of Chromium Complexes and ORTEP Drawings.}

in $51 \%$ yield. By contrast, the reaction of 1 a with 1 equiv of $\mathrm{NaBAr}_{4}\left(\mathrm{Ar}^{\mathrm{F}}=3,5\right.$-bis(trifluoromethyl)phenyl) gave the corresponding cationic chromium complex [CrCl(PCP)]BArF ${ }_{4}$ (2a). Notably, the crystal structure of $\mathbf{2 a}$ is characterized with a distorted square-planar geometry around the chromium atom; the value of the geometry index $\tau_{4}$ for this structure was 0.18 ; indeed, $\tau_{4}$ ranges from 0.00 , corresponding to an ideal squareplanar geometry, to 1.00 , corresponding to an ideal tetrahedral geometry. ${ }^{21}$ The chloride ligand of $\mathbf{2 a}$ could be exchanged with an iodide ligand as a result of the reaction of $2 \mathbf{a}$ with an excess amount of $\mathrm{NaI}$ to give the corresponding iodide complex $[\mathrm{CrI}(\mathrm{PCP})] \mathrm{BArF}_{4}(\mathbf{2 b}) . \quad \mathbf{1 a}, \mathbf{1 b}, \mathbf{2 a}$, and $\mathbf{2} \mathbf{b}$ were observed to have values for the solution magnetic moments of $4.5 \mu_{B}, 5.1 \mu_{B}$, $5.4 \mu_{\mathrm{B}}$, and $4.8 \mu_{\mathrm{B}}$ (as measured by Evans method ${ }^{22}$ ), respectively, which indicate that these complexes are characterized by a $S=2$ spin state $\left(4.9 \mu_{\mathrm{B}}\right)$ (see Supporting Information).

In order to obtain the corresponding chromium-dinitrogen complex, we carried out reduction of $\mathbf{1} \mathbf{a}$ under dinitrogen. The reaction of $1 \mathrm{a}$ with 2 equiv of $\mathrm{KC}_{8}$ in $\mathrm{THF}$ at $-30{ }^{\circ} \mathrm{C}$ for $0.5 \mathrm{~h}$ under $1 \mathrm{~atm}$ of dinitrogen gave a dark purple solution. After recrystallization from THF-pentane at $-30{ }^{\circ} \mathrm{C}$, the corresponding dinitrogen-bridged dichromium complex $\left[\mathrm{Cr}\left(\mathrm{N}_{2}\right)(\mathrm{PCP})\right]_{2}\left(\mu-\mathrm{N}_{2}\right)$ (3) was obtained as a brown crystalline solid in $65 \%$ yield (Scheme 1). IR spectrum of $\mathbf{3}$ showed a strong absorption attributable to $v(\mathrm{NN})$ band at $1897 \mathrm{~cm}^{-1}$. The detailed structure of $\mathbf{3}$ was unambiguously determined by X-ray crystallography. An ORTEP drawing is shown in Scheme 1. The chromium centers in $\mathbf{3}$ have a square pyramidal geometry with PCP, terminal dinitrogen, and bridging dinitrogen ligands. The $\left[\mathrm{Cr}\left(\mathrm{N}_{2}\right)(\mathrm{PCP})\right]$ fragments are bridged by a dinitrogen ligand with an end-on fashion.

Next, the corresponding chromium-nitride complex was prepared from 1a (Scheme 1). The reaction of $1 \mathbf{a}$ with the manganese-nitride complex $[\mathrm{Mn}(\mathrm{N})($ salen $)]$ (salen $=N, N^{\prime}$-bis(2-hydroxybenzylidene)ethylenediamine) proceeded via a nitride transfer reaction, ${ }^{23}$ which was followed by an anion exchange with $\mathrm{NaBAr}^{\mathrm{F}}$, resulting in the formation of the cationic chromium-nitride complex $[\mathrm{CrCl}(\mathrm{N})(\mathrm{PCP})] \mathrm{BAr}^{\mathrm{F}}{ }_{4}(4)$ in $62 \%$ yield. The detailed structure of $\mathbf{4}$ was unambiguously determined by X-ray crystallography (Scheme 1).

The catalytic reduction of dinitrogen to produce ammonia using these chromium complexes was carried out under the reported conditions of catalytic nitrogen fixation. ${ }^{6 \mathrm{~d}, 8,10,13}$ The reaction with 36 equiv of $\mathrm{SmI}_{2}$ and 36 equiv of water with respect to the chromium-based catalyst in the presence of $\mathbf{4}$ under atmospheric pressure of dinitrogen in THF at room temperature for $20 \mathrm{~h}$ afforded 0.52 equiv of ammonia based on the chromium atom (Table 1 , run 1 ). The analogous reaction conducted with 40 equiv of $\mathrm{CoCp}_{2}{ }_{2}\left(\mathrm{Cp}^{*}=\eta^{5}-\mathrm{C}_{5}\left(\mathrm{CH}_{3}\right)_{5}\right)$, acting as a reductant, and 36 equiv of $\left[\mathrm{Ph}_{2} \mathrm{NH}_{2}\right] \mathrm{OTf}\left(\mathrm{OTf}=\mathrm{OS}(\mathrm{O})_{2} \mathrm{CF}_{3}\right)$, acting as a proton source, at $-78{ }^{\circ} \mathrm{C}$ for $2 \mathrm{~h}$ afforded 0.61 equivalents of ammonia based on the chromium atom (Table 1, run 2). The combination of $\mathrm{KC}_{8}$ and $\left[\mathrm{H}\left(\mathrm{Et}_{2} \mathrm{O}\right)_{2}\right] \mathrm{BArF}_{4}$ as a reductant and proton source, respectively, also yielded a stoichiometric amount of ammonia and a small amount of hydrazine as a minor product (Table 1, run 3). On the other hand, the reaction conducted under the conditions reported by Liddle, ${ }^{13}$ whereby $\mathrm{KC}_{8}$ and $\left[\mathrm{PCy}{ }_{3} \mathrm{H}\right] \mathrm{I}$ were used as reagents, afforded 4.15 equiv of ammonia and 0.09 equiv of hydrazine (4.33 equiv of fixed $\mathrm{N}$ atom) based on the chromium atom, respectively (Table 1 , run 4). Notably, the efficiency of the catalytic reaction was observed to depend on the counter-anion of the phosphonium salt. Although $\left[\mathrm{PCy}_{3} \mathrm{H}\right] \mathrm{Cl}$ did not work as an effective proton source, $\left[\mathrm{PCy}{ }_{3} \mathrm{H}\right] \mathrm{OTf},\left[\mathrm{PCy}{ }_{3} \mathrm{H}\right] \mathrm{BArF}_{4}$, and $\left[\mathrm{PCy}_{3} \mathrm{H}\right] \mathrm{BF}_{4}$ performed well the said role. In fact, use of [ $\mathrm{PCy}_{3} \mathrm{H}_{3} \mathrm{BF}_{4}$ as a proton source gave the best results, with 5.26 equiv of ammonia and 0.04 equiv of hydrazine (5.34 equiv of fixed $\mathrm{N}$ atom) produced based on the chromium atom (Table 1 , runs 5-8). 
Table 1. Catalytic Reduction of $\mathrm{N}_{2}$ to $\mathrm{NH}_{3}$ and $\mathrm{N}_{2} \mathrm{H}_{4}$ Using Chromium Complexes. ${ }^{a}$

\begin{tabular}{|c|c|c|c|c|c|c|c|c|c|}
\hline \multirow{3}{*}{$\begin{array}{c}\mathrm{N}_{2} \\
1 \mathrm{~atm}\end{array}$} & \multirow[t]{2}{*}{+} & \multirow{2}{*}{\multicolumn{2}{|c|}{$\begin{array}{c}\mathrm{e}^{-} \\
\text {reductant }\end{array}$}} & \multirow{2}{*}{$\begin{array}{c}\mathrm{H}^{+} \\
\text {proton } \\
\text { source }\end{array}$} & \multirow{2}{*}{$\begin{array}{c}\stackrel{\text { Cr catalyst }}{\longrightarrow} \\
\mathrm{Et}_{2} \mathrm{O} \\
-78^{\circ} \mathrm{C} \text { to rt } \\
1 \mathrm{~h} \text { to } 1 \mathrm{~h}\end{array}$} & \multirow[t]{3}{*}{$\mathrm{NH}_{3}$} & \multirow[t]{3}{*}{+} & \multirow[t]{3}{*}{$\mathrm{N}_{2} \mathrm{H}_{4}$} & \multirow{3}{*}{$\left(+\mathrm{H}_{2}\right.$} \\
\hline & & & & & & & & & \\
\hline & & 40 equiv/ $\mathrm{Cr}$ & & 36 equiv/Cr & & & & & \\
\hline
\end{tabular}

\begin{tabular}{|c|c|c|c|c|c|c|c|}
\hline run & $\begin{array}{c}\mathrm{Cr} \\
\text { catalyst }\end{array}$ & reductant & $\begin{array}{l}\text { proton } \\
\text { source }\end{array}$ & $\begin{array}{c}\mathrm{NH}_{3} \\
\text { (equiv/Cr) }\end{array}$ & $\begin{array}{c}\mathrm{N}_{2} \mathrm{H}_{4} \\
\text { (equiv/Cr) }\end{array}$ & $\begin{array}{l}\text { fixed nitrogen atom } \\
\text { (equiv/Cr) }\end{array}$ & $\begin{array}{c}\mathrm{H}_{2} \\
\text { (equiv/Cr) }\end{array}$ \\
\hline $1^{b}$ & 4 & $\mathrm{SmI}_{2}$ & $\mathrm{H}_{2} \mathrm{O}$ & 0.52 & 0 & 0.52 & 0.92 \\
\hline $2^{c}$ & 4 & $\mathrm{CoCp}_{2}$ & {$\left[\mathrm{Ph}_{2} \mathrm{NH}_{2}\right] \mathrm{OTf}$} & 0.61 & 0 & 0.61 & 5.98 \\
\hline 3 & 4 & $\mathrm{KC}_{8}$ & {$\left[\mathrm{H}\left(\mathrm{Et}_{2} \mathrm{O}\right)_{2}\right] \mathrm{BAr}_{4}^{\mathrm{F}}$} & 1.68 & 0.08 & 1.84 & 5.95 \\
\hline 4 & 4 & $\overline{\mathrm{KC}_{8}}$ & {$\left[\mathrm{PCy}_{3} \mathrm{H}\right] \mathrm{I}$} & 4.15 & 0.09 & 4.33 & 3.36 \\
\hline 5 & 4 & $\mathrm{KC}_{8}$ & {$\left[\mathrm{PCy}_{3} \mathrm{H}\right] \mathrm{Cl}$} & 1.24 & 0.2 & 1.64 & 2.09 \\
\hline 6 & 4 & $\overline{\mathrm{KC}_{8}}$ & {$\left[\mathrm{PCy}_{3} \mathrm{H}\right] \mathrm{OTf}$} & 3.84 & 0.01 & 3.86 & 4.87 \\
\hline 7 & 4 & $\overline{\mathrm{KC}_{8}}$ & {$\left[\mathrm{PCy}_{3} \mathrm{H}\right] \mathrm{BAr}_{4}^{\mathrm{F}}$} & 2.98 & 0.21 & 3.4 & 5.42 \\
\hline 8 & 4 & $\mathrm{KC}_{8}$ & {$\left[\mathrm{PCy}_{3} \mathrm{H}\right] \mathrm{BF}_{4}$} & 5.26 & 0.04 & 5.34 & 1.57 \\
\hline 9 & $1 \mathrm{a}$ & $\mathrm{KC}_{8}$ & {$\left[\mathrm{PCy}_{3} \mathrm{H}\right] \mathrm{I}$} & 0.77 & 0.13 & 1.03 & 1.75 \\
\hline 10 & $1 \mathrm{~b}$ & $\mathrm{KC}_{8}$ & {$\left[\mathrm{PCy}_{3} \mathrm{H}\right] \mathrm{I}$} & 0.95 & 0.18 & 1.31 & 2.01 \\
\hline 11 & $2 a$ & $\mathrm{KC}_{8}$ & {$\left[\mathrm{PCy}_{3} \mathrm{H}\right] \mathrm{I}$} & 1.06 & 0.09 & 1.24 & 3.45 \\
\hline 12 & 3 & $\mathrm{KC}_{8}$ & {$\left[\mathrm{PCy}_{3} \mathrm{H}\right] \mathrm{I}$} & 0.66 & 0 & 0.66 & 0.6 \\
\hline 13 & $2 \mathrm{~b}$ & $\mathrm{KC}_{8}$ & {$\left[\mathrm{PCy}_{3} \mathrm{H}\right] \mathrm{I}$} & 5.12 & 0.9 & 6.92 & 1.18 \\
\hline 14 & $2 \mathrm{~b}$ & $\mathrm{KC}_{8}$ & {$\left[\mathrm{PCy}_{3} \mathrm{H}\right] \mathrm{BF}_{4}$} & $4.87 \pm 0.39^{d}$ & $1.07 \pm 0.50^{d}$ & 7.01 & $2.01 \pm 0.27^{d}$ \\
\hline $15^{e}$ & $2 \mathrm{~b}$ & $\mathrm{KC}_{8}$ & {$\left[\mathrm{PCy}_{3} \mathrm{H}\right] \mathrm{BF}_{4}$} & $8.40 \pm 3.25^{d}$ & $2.46 \pm 1.21^{d}$ & 13.3 & $16.3 \pm 4.5^{d}$ \\
\hline
\end{tabular}

${ }^{a}$ A mixture of $\mathrm{Cr}$ complex $(0.01 \mathrm{mmol})$, reductant $(0.40 \mathrm{mmol}, 40$ equiv based on the $\mathrm{Cr}$ atom $)$ and proton source $(0.36 \mathrm{mmol}, 36$ equiv based on the $\mathrm{Cr}$ atom $)$ in $\mathrm{Et}_{2} \mathrm{O}(5 \mathrm{~mL})$ at $-78^{\circ} \mathrm{C}$ was stirred for $1 \mathrm{~h}$ under $1 \mathrm{~atm}$ of dinitrogen, followed by stirring at room temperature for another $1 \mathrm{~h}$. ${ }^{b}$ To a mixture of $\mathrm{Cr}$ complex $(0.01 \mathrm{mmol})$ and $\mathrm{SmI}_{2}$ (THF) $)_{2}(0.36 \mathrm{mmol}, 36$ equiv based on the $\mathrm{Cr}$ atom $)$ in the THF (5.0 mL) was added the THF solution $(1 \mathrm{~mL})$ containing water $(0.36 \mathrm{mmol}, 36$ equiv based on the $\mathrm{Cr}$ atom) in one portion at room temperature, followed by stirring at room temperature for $20 \mathrm{~h}$ under $1 \mathrm{~atm}$ of dinitrogen. ${ }^{c}$ The reaction time is $1 \mathrm{~h}$ at $-78^{\circ} \mathrm{C}$ and $19 \mathrm{~h}$ at room temperature. $d$ The values were determined as the mean of multiple individual experiments (at least two) with error bars (s.d.). ${ }^{e}$ The larger amounts of $\mathrm{KC}_{8}$ ( 200 equiv based on the $\mathrm{Cr}$ atom) and $\left[\mathrm{PCy}_{3} \mathrm{H}\right] \mathrm{BF}_{4}$ (180 equiv based on the $\mathrm{Cr}$ atom) were used.

Next, reactions conducted in the presence $\mathrm{KC}_{8}$ and $\left[\mathrm{PCy}_{3} \mathrm{H}\right] \mathrm{I}$ using various chromium complexes were investigated. The neutral chromium(II) dihalide complexes $\mathbf{1 a}$ and $\mathbf{1 b}$, the cationic chromium(II) chloride complex $\mathbf{2 a}$, and the dinitrogenbridged dichromium(0) complex $\mathbf{3}$ did not work well as catalysts (Table 1 runs 9-12). We consider that no catalytic activity of $\mathbf{3}$ is due to the low solubility of $\mathbf{3}$ in diethyl ether $\left(\mathrm{Et}_{2} \mathrm{O}\right)$. However, the reaction whereby the cationic chromium(II) iodide complex $\mathbf{2 b}$ was used as a catalyst yielded 5.12 equiv of ammonia based on the chromium atom and 0.90 equiv of hydrazine (6.92 equiv of fixed $\mathrm{N}$ atom) (Table 1 , run 13). Finally, the amount of nitrogen atoms undergoing fixation reached a value of 7.01 equiv based on the chromium atom in the reaction conducted in the presence of $\mathrm{KC}_{8}$ and $\left[\mathrm{PCy}_{3} \mathrm{H}_{3} \mathrm{BF}_{4}\right.$, using $\mathbf{2} \mathbf{b}$ as catalyst; in this case, 4.87 equiv of ammonia and 1.07 equiv of hydrazine were produced, based on the catalyst (Table 1, run 14). Notably, by conducting the catalytic reaction in the presence of larger amounts of $\mathrm{KC}_{8}$ and $\left[\mathrm{PCy}_{3} \mathrm{H}\right] \mathrm{BF}_{4}$ using $\mathbf{2} \mathbf{b}$ as a catalyst, up to 8.40 equiv of ammonia and 2.46 equiv of hydrazine
(13.32 equiv of fixed $\mathrm{N}$ atom) were obtained based on the chromium atom (Table 1, run 15). Separately, we confirmed the direct conversion of molecular dinitrogen to ammonia and hydrazine when $\mathbf{2 b}$ was used a catalyst in a reaction conducted under atmospheric pressure of ${ }^{15} \mathrm{~N}_{2}$ gas, in place of the regular ${ }^{14} \mathrm{~N}_{2}$ gas (see Supporting Information).

In order to gain insight into the reaction mechanism, a stoichiometric reaction of $\mathbf{4}$ was carried out. The reaction of $\mathbf{4}$ with 6 equiv of $\mathrm{KC}_{8}$ and 5 equiv of $\left[\mathrm{PCy}_{3} \mathrm{H}\right] \mathrm{BF}_{4}$ in $\mathrm{Et}_{2} \mathrm{O}$ at $-78^{\circ} \mathrm{C}$ for 2 $\mathrm{h}$ under argon atmosphere produced ammonia in $83 \%$ yield based on the nitride ligand in $\mathbf{4}$ without the formation of hydrazine (Scheme 2). Although ammonia may form from the chromium-nitride complexes acting as reactive intermediates in the catalytic reactions, hydrazine detected in the catalytic reactions is confirmed not to be produced via chromium-nitride complexes. 


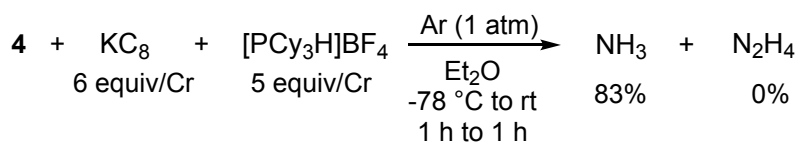

Scheme 2. Stoichiometric Reaction of Chromium-Nitride Complex.

The isolation of chromium-dinitrogen complex such as $\mathbf{3}$ and the conversion of dinitrogen to ammonia and hydrazine catalyzed by $\mathbf{2 b}$ might be reminiscent of the reactivity of planar four-coordinate Fe and Co complexes bearing a pyrrole-based PNP-pincer ligand (Scheme 3).9a,11 We previously reported

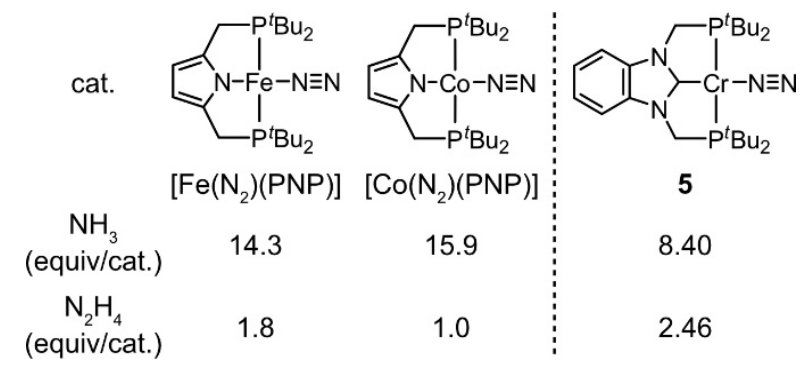

\section{Scheme 3. Catalytic Activity of $\mathrm{M}-\mathrm{N}_{2}$ Complexes (M =} $\mathrm{Fe},{ }^{9 a} \mathrm{Co}^{11}$ ) and a Possible $\mathrm{Cr}-\mathrm{N}_{2}$ Complex.

that these metal- $\mathrm{N}_{2}$ complexes served as catalysts for the conversion of dinitrogen to ammonia and hydrazine. ${ }^{9 a, 11}$ Based on previously reported findings, we would like to propose the planar four-coordinate $\mathrm{Cr}-\mathrm{N}_{2}$ complex [ $\left.\mathrm{Cr}\left(\mathrm{N}_{2}\right)(\mathrm{PCP})\right]$ (5) as an active dinitrogen species and discuss possible reaction pathways for the formation of $\mathbf{5}$ from $\mathbf{2 b}$ with the aid of DFT calculations at the B3LYP-D3 level of theory (see Supporting Information). The $\Delta G_{195}$ value of the reaction $\mathbf{2 b}+\mathrm{N}_{2}+2 \mathrm{e}^{-} \rightarrow \mathbf{5}+\mathrm{I}^{-}$is calculated to be $+0.3 \mathrm{kcal} / \mathrm{mol}$ in $\mathrm{Et}_{2} \mathrm{O}$, indicating that, from a thermodynamic standpoint, the formation of $\mathbf{5}$ is likely to occur.

Figure 1 shows free energy profiles of three possible pathways for the transformation of $\mathbf{2 b}$ into $\mathbf{5}$ involving two-electron reduction, coordination of $\mathrm{N}_{2}$, and release of $\mathrm{I}^{-}$. In Path $\mathbf{A}$, a dinitrogen molecule coordinates to $\left[\mathbf{C r} \mathbf{r I}^{\mathrm{II}}(\mathrm{I})\right]+\mathbf{2} \mathbf{b}(\mathbf{C r}=[\mathrm{Cr}(\mathrm{PCP})])$, and then the five-coordinate $\mathrm{Cr}^{\mathrm{II}}-\mathrm{N}_{2}$ complex $\mathbf{6}$ is reduced by two electrons. However, a large positive value of $\Delta G_{195}$ for $\mathbf{2 b}$ $\rightarrow 6(+30.7 \mathrm{kcal} / \mathrm{mol})$ indicates that the $\mathrm{N}_{2}$ coordination to the

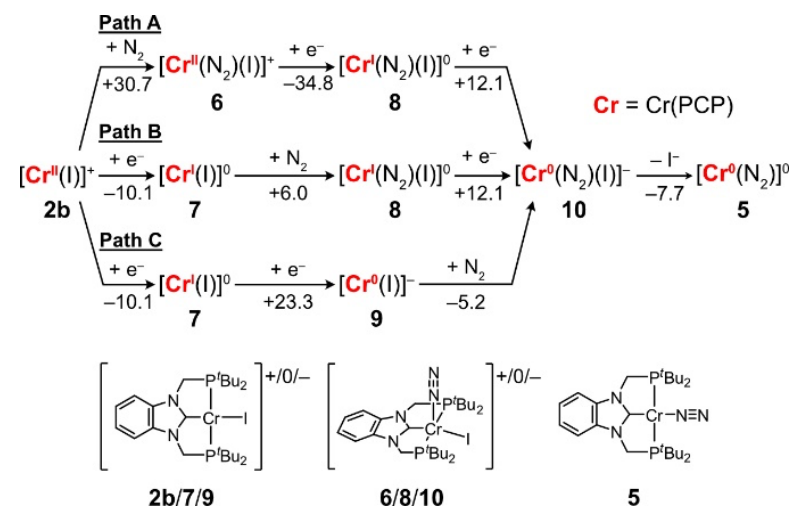

Figure 1. Free Energy Profiles $\left(\Delta G_{195}\right.$ in $\left.\mathrm{kcal} / \mathrm{mol}\right)$ of Three Possible Reaction Pathways for Transformation of $2 b$ to 5 .
CrII center is thermodynamically unfavorable. In Paths B and C, reduction of $\mathbf{2 b}$ is exergonic by $10.1 \mathrm{kcal} / \mathrm{mol}$. The four-coordinate $\mathrm{Cr}^{\mathrm{I}}$ complex [C-ri $\left.\left.{ }^{\mathrm{I}} \mathrm{I}\right)\right] \mathbf{7}$ undergoes $\mathrm{N}_{2}$ coordination and reduction to afford the five-coordinate $\mathrm{Cr}^{0}$ complex $\left[\mathbf{C r}^{0}\left(\mathrm{~N}_{2}\right)(\mathrm{I})\right]^{-} \mathbf{1 0}$. These two steps are totally endergonic by $18.1 \mathrm{kcal} / \mathrm{mol}$. In the final step, the release of I- from 10 yields the $\mathrm{Cr}^{0}-\mathrm{N}_{2}$ complex $5\left(\Delta G_{195}=-7.7 \mathrm{kcal} / \mathrm{mol}\right)$. Protonation of 5 by $\left[\mathrm{PCy}_{3} \mathrm{H}\right]^{+}$will smoothly proceed at $195 \mathrm{~K}\left(\Delta G_{195}=-4.8\right.$ $\mathrm{kcal} / \mathrm{mol}$ and $\Delta G^{\ddagger}=0.8 \mathrm{kcal} / \mathrm{mol}$ (see Figure S14 in Supporting Information). At present, Path $\mathbf{B}$ could be the most probable pathway, because it comprises no highly endergonic reaction steps.

We also theoretically examined the possibility of direct $\mathrm{N} \equiv \mathrm{N}$ bond cleavage of $\mathrm{N}_{2}$ by two $\mathrm{Cr}$ cores. In our previous works on catalytic ammonia formation using molybdenum complexes bearing the same pincer-type ligand, $6 c, 6 \mathrm{~d}, 24$ the direct $\mathrm{N} \equiv \mathrm{N}$ bond cleavage of [MoII(PNP) $]_{2}\left(\mu-\mathrm{N}_{2}\right)$ (PNP $=2,6$-bis((di-tert-butylphosphinomethyl)pyridine) was proposed as a key reaction step. Figure 2 presents a free energy profile at $195 \mathrm{~K}$ calculated for the direct $\mathrm{N} \equiv \mathrm{N}$ bond cleavage of a dinitrogen-bridged dichromium complex $\left[\mathrm{Cr}^{\mathrm{I}} \mathrm{I}(\mathrm{PCP})\right]_{2}\left(\mu-\mathrm{N}_{2}\right)$ 11, a structural analog of $[\mathrm{Mo} I(\mathrm{PNP})]_{2}\left(\mu-\mathrm{N}_{2}\right)$. The ground spin state of complex $\mathbf{1 1}$ is a high-spin septet, while both the resulting $\mathrm{Cr}$-nitride complex [CrIVI(N)(PCP)] 12 and the transition state $\mathbf{T S}_{\mathbf{1 1} / \mathbf{1 2}}$ connecting 11 and 12 favor the lowest spin state. We were not able to optimize $\mathbf{T S}_{\mathbf{1 1} / \mathbf{1 2}}$ at the quintet and septet states. As a result, the direct $\mathrm{N} \equiv \mathrm{N}$ cleavage of $\mathbf{1 1}$ is highly endergonic $\left(\Delta G_{195}=46.9\right.$ $\mathrm{kcal} / \mathrm{mol}$ ) with an extremely high activation free energy (at least $81.2 \mathrm{kcal} / \mathrm{mol}$ ). Thus, we can exclude the reaction mechanism via the direct $\mathrm{N} \equiv \mathrm{N}$ bond cleavage of $\mathrm{N}_{2}$ in the Cr-catalytic system (see Supporting Information for a proposed reaction pathway in Scheme S1).

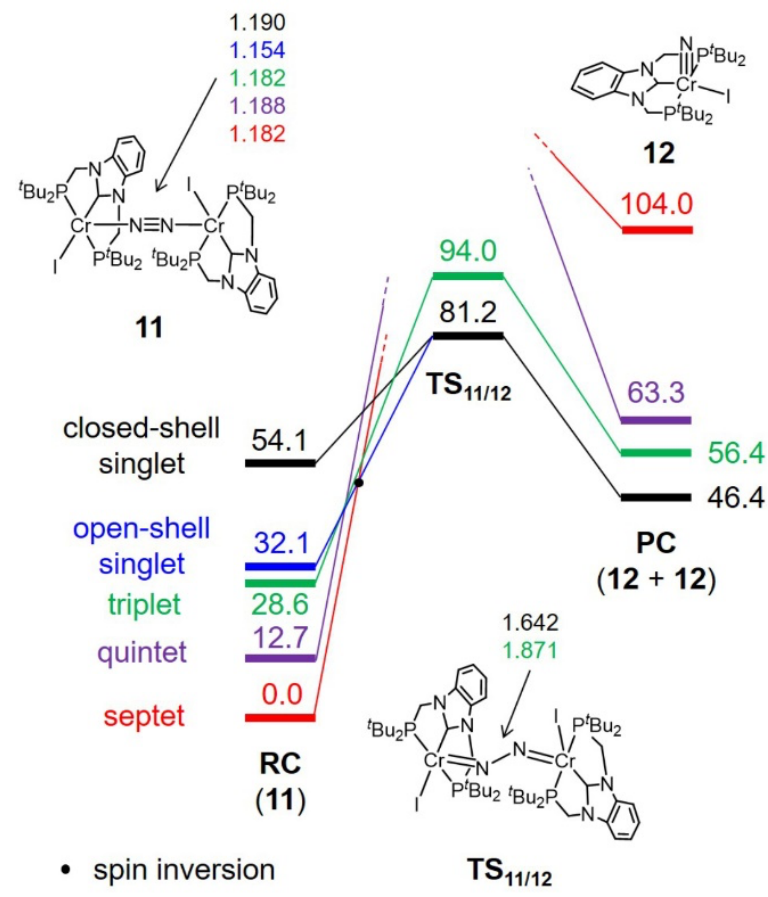

Figure 2. Free Energy Changes $\left(\Delta G_{195}\right.$ in $\left.\mathrm{kcal} / \mathrm{mol}\right)$ in the $\mathrm{N} \equiv \mathrm{N}$ Bond Cleavage of 11 Yielding a Couple of 12 . 
In summary, we have found the chromium-catalyzed reduction of dinitrogen into ammonia and hydrazine under mild reaction conditions. The use of the chromium complexes bearing a PCP-type pincer ligand provides the first successful example of the catalytic and direct conversion of dinitrogen into ammonia and hydrazine, in contrast to well studies on the catalytic formation of silylamine using chromium-dinitrogen complexes bearing other ligands. Further investigation on the mechanistic study to elucidate the reaction pathway and the development of more effective chromium catalysts is now in progress.

\section{ASSOCIATED CONTENT}

\section{Supporting Information}

The Supporting Information is available free of charge on the ACS Publications website.

\section{AUTHOR INFORMATION}

\section{Corresponding Author}

*ynishiba@g.ecc.u-tokyo.ac.jp

*kazunari@ms.ifoc.kyushu-u.ac.jp

Notes

The authors declare no competing financial interest.

\section{ACKNOWLEDGMENT}

The present project is supported by CREST, JST (JPMJCR1541). We acknowledge Grants-in-Aids for Scientific Research (Nos. JP20H05671 and 20K21203) from JSPS and MEXT. Y.A. is a recipient of the JSPS Predoctoral Fellowships for Young Scientists.

\section{REFERENCES}

(1) Liu, H. Ammonia Synthesis Catalysts, Innovation and Practice; Chemical Industry Press and World Scientific: Singapore and Beijing, 2013.

(2) (a) Nitrogen Fixation: Methods and Protocols; Ribbe, M. W. Ed.; Humana Press: New York, 2011. (b) Bioinspired Catalysis: Metal-Sulfur Complexes; Weigand, W.; Schollhammer, P. Eds.; Wiley-VCH: Weinheim, 2015.

(3) (a) Nitrogen Fixation (Topics in Organometallic Chemistry 60), Ed.; Nishibayashi, Y. Springer, Cham, 2017. (b) Transition Metal-Dinitrogen Complexes: Preparation and Reactivity; Ed. Nishibayashi, Y. Wiley-VCH: Weinheim, 2019.

(4) For selected reviews on nitrogen fixations catalyzed by transition metal-dinitrogen complexes, see: (a) Flöser, B. M.; Tuczek, F. Synthetic Nitrogen Fixation with Mononuclear Molybdenum Complexes: Electronic-Structural and Mechanistic Insights from DFT. Coord. Chem. Rev. 2017, 345, 263-280. (b) Burford, R. J.; Fryzuk, M. D. Examining the Relationship between Coordination Mode and Reactivity of Dinitrogen. Nat. Rev. Chem. 2017, 1, 0026. (c) Foster, S. L.; Bakovic, S. I. P.; Duda, R. D.; Maheshwari, S.; Milton, R. D.; Minteer, S. D.; Janik, M. J.; Renner, J. N. Catalysts for Nitrogen Reduction to Ammonia. Nat. Catal. 2018, 1, 490500. (d) Stucke, N.; Flöser, B. M.; Weyrich, T.; Tuczek, F. Nitrogen Fixation Catalyzed by Transition Metal Complexes: Recent Developments. Eur. J. Inorg. Chem. 2018, 2018, 1337-1355. (e) Nishibayashi, Y. Development of Catalytic Nitrogen Fixation Using Transition Metal-Dinitrogen Complexes under Mild Reaction Conditions. Dalton Trans. 2018, 47, 11290-11297. (f) Chalkley, M. J.; Peters, J. C. Relating N-H Bond Strengths to the Overpotential for Catalytic Nitrogen Fixation. Eur. J. Inorg. Chem. 2020, 2020, 1353-1357. (g) Kendall, A. J.; Mock, M. T. Dinitrogen Activation and Functionalization with Chromium. Eur. J. Inorg. Chem. 2020, 2020, 1358-1375. (h) Sivasankar, C.; Madarasi, P. K.; Tamizmani, M. Activation and Functionalization of Dinitrogen in the Presence of Molecular Hydrogen Promoted by Transition Metal Complexes. Eur. J. Inorg. Chem. 2020, 2020, 1383-1395. (i) Chalkley, M. J.; Drover, M. W.; Peters, J. C. Catalytic $\mathrm{N}_{2}-$ to- $\mathrm{NH}_{3}\left(\right.$ or $-\mathrm{N}_{2} \mathrm{H}_{4}$ ) Conversion by
Well-Defined Molecular Coordination Complexes. Chem. Rev. 2020, 120 , 5582-5639. (j) Tanifuji, K.; Ohki, Y. Metal-Sulfur Compounds in N2 Reduction and Nitrogenase-Related Chemistry. Chem. Rev. 2020, 120, 5194-5251. (k) Singh, D.; Buratto, W. R.; Torres, J. F.; Murray, L. J. Activation of Dinitrogen by Polynuclear Metal Complexes. Chem. Rev. 2020, 120, 5517-5581. (1) Ashida, Y.; Nishibayashi, Y. Catalytic Conversion of Nitrogen Molecule into Ammonia Using Molybdenum Complexes under Ambient Reaction Conditions. Chem. Commun. 2021, 57, 1176-1189. (m) Kuriyama, S.; Nishibayshi, Y. Development of Catalytic Nitrogen Fixation Using Transition Metal Complexes not Relevant to Nitrogenases. Tetrahedron 2021, 83, 131986. (n) Tanabe, Y.; Nishibayshi, Y. Comprehensive Insights into Synthetic Nitrogen Fixation Assisted by Molecular Catalysts under Ambient or Mild Conditions. Chem. Soc. Rev. 2021, 50, 5201-5242. (o) Forrest, S. J. K.; Schluschaß, B.; Yuzik-Klimova, E. Y.; Schneider, S. Nitrogen Fixation via Splitting into Nitrido Complexes. Chem. Rev. 2021, 121, 6522-6587.

(5) (a) Yandulov, D. V.; Schrock, R. R. Catalytic Reduction of Dinitrogen to Ammonia at a Single Molybdenum Center. Science 2003, 301, 76-78. (b) Ritleng, V.; Yandulov, D. V.; Weare, W. W.; Schrock, R. R.; Hock, A. S.; Davis, W. M. Molybdenum Triamidoamine Complexes that Contain Hexa-tert-butylterphenyl, Hexamethylterphenyl, or $p$-Bromohexaisopropylterphenyl Substituents. An Examination of Some Catalyst Variations for the Catalytic Reduction of Dinitrogen. J. Am. Chem. Soc. 2004, 126, 6150-6163. (c) Schrock, R. R. Catalytic Reduction of Dinitrogen to Ammonia at a Single Molybdenum Center. Acc. Chem. Res. 2005, 38, 955-962. (d) Schrock, R. R. Catalytic Reduction of Dinitrogen to Ammonia by Molybdenum: Theory versus Experiment. Angew. Chem., Int. Ed. 2008, 47, 5512-5522. (e) Wickramasinghe, L. A.; Ogawa, T.; Schrock, R. R.; Müller, P. Reduction of Dinitrogen to Ammonia Catalyzed by Molybdenum Diamido Complexes. J. Am. Chem. Soc. 2017, 139, 9132-9135.

(6) (a) Arashiba, K.; Miyake, Y.; Nishibayashi, Y. A Molybdenum Complex Bearing PNP-Type Pincer Ligands Leads to the Catalytic Reduction of Dinitrogen into Ammonia. Nat. Chem. 2011, 3, 120-125. (b) Eizawa, A.; Arashiba, K.; Tanaka, H.; Kuriyama, S.; Matsuo, Y.; Nakajima, K.; Yoshizawa, K.; Nishibayashi, Y. Remarkable Catalytic Activity of Dinitrogen-Bridged Dimolybdenum Complexes Bearing NHC-Based PCPPincer Ligands toward Nitrogen Fixation. Nat. Commun. 2017, 8, 14874. (c) Arashiba, K.; Eizawa, A.; Tanaka, H.; Nakajima, K.; Yoshizawa, K.; Nishibayashi, Y. Catalytic Nitrogen Fixation via Direct Cleavage of Nitrogen-Nitrogen Triple Bond of Molecular Dinitrogen under Ambient Reaction Conditions. Bull. Chem. Soc. Jpn. 2017, 90, 1111-1118. (d) Ashida, Y.; Arashiba, K.; Nakajima, K.; Nishibayashi, Y. MolybdenumCatalysed Ammonia Production with Samarium Diiodide and Alcohols or Water. Nature 2019, 568, 536-540. (e) Ashida, Y.; Arashiba, K.; Tanaka, H.; Egi, A.; Nakajima, K.; Yoshizawa, K.; Nishibayashi, Y. Molybdenum-Catalyzed Ammonia Formation Using Simple Monodentateand Bidentate-Phosphines as Auxiliary Ligands. Inorg. Chem. 2019, 58, 3792-3795.

(7) Engesser, T. A.; Kindjajev, A.; Junge, J.; Krahmer, J.; Tuczek, F. A Chatt - Type Catalyst with One Coordination Site for Dinitrogen Reduction to Ammonia. Chem. - Eur. J., 2020, 26, 14807-14812.

(8) (a) Anderson, J. S.; Rittle, J.; Peters, J. C. Catalytic Conversion of Nitrogen to Ammonia by an Iron Model Complex. Nature 2013, 501, 84-87. (b) Ung, G.; Peters, J. C. Low - Temperature $\mathrm{N}_{2}$ Binding to Two Coordinate $\mathrm{L}_{2} \mathrm{Fe}^{0}$ Enables Reductive Trapping of $\mathrm{L}_{2} \mathrm{FeN}_{2}{ }^{-}$and $\mathrm{NH}_{3} \mathrm{Gen}$ eration. Angew. Chem., Int. Ed. 2015, 54, 532-535. (c) Del Castillo, T. J.; Thompson, N. B.; Peters, J. C. A Synthetic Single-Site Fe Nitrogenase: High Turnover, Freeze-Quench ${ }^{57} \mathrm{Fe}$ Mössbauer Data, and a Hydride Resting State. J. Am. Chem. Soc. 2016, 138, 5341-5350. (d) Buscagan, T. M.; Oyala, P. H.; Peters, J. C. $\mathrm{N}_{2}$-to- $\mathrm{NH}_{3}$ Conversion by a Triphos-Iron Catalyst and Enhanced Turnover under Photolysis. Angew. Chem., Int. Ed. 2017, 56, 6921-6926. (e) Chalkley, M. J.; Del Castillo, T. J.; Matson, B. D.; Roddy, J. P.; Peters, J. C. Catalytic $\mathrm{N}_{2}$-to- $\mathrm{NH}_{3}$ Conversion by $\mathrm{Fe}$ at Lower Driving Force: A Proposed Role for Metallocene-Mediated PCET. ACS Cent. Sci. 2017, 3, 217-223.

(9) (a) Kuriyama, S.; Arashiba, K.; Nakajima, K.; Matsuo, Y.; Tanaka, H.; Ishii, K.; Yoshizawa, K.; Nishibayashi, Y. Catalytic Tranformation of Dinitrogen into Ammonia and Hydrazine by Iron- Dinitrogen Complexes Bearing Pincer Ligand. Nat. Commun. 2016, 7, 12181. (b) 
Sekiguchi, Y.; Kuriyama, S.; Eizawa, A.; Arashiba, K.; Nakajima, K.; Nishibayashi, Y. Synthesis and Reactivity of Iron-Dinitrogen Complexes Bearing Anionic Methyl- and Phenyl-Substituted Pyrrole-Based PNPType Pincer Ligands toward Catalytic Nitrogen Fixation. Chem. Commun. 2017, 53, 12040-12043. (c) Higuchi, J.; Kuriyama, S.; Eizawa, A.; Arashiba, K.; Nakajima, K.; Nishibayashi, Y. Preparation and Reactivity of Iron Complexes Bearing Anionic Carbazole-Based PNP-Type Pincer Ligands toward Catalytic Nitrogen Fixation. Dalton Trans. 2018, 47, 1117-1121.

(10) Hill, P. J.; Doyle, L. R.; Crawford, A. D.; Myers, W. K.; Ashley, A. E. Selective Catalytic Reduction of $\mathrm{N}_{2}$ to $\mathrm{N}_{2} \mathrm{H}_{4}$ by a Simple Fe Complex. J. Am. Chem. Soc. 2016, 138, 13521-13524.

(11) Kuriyama, S.; Arashiba, K.; Tanaka, H.; Matsuo, Y.; Nakajima, K.; Yoshizawa, K.; Nishibayashi, Y. Direct Transformation of Molecular Dinitrogen into Ammonia Catalyzed by Cobalt Dinitrogen Complexes Bearing Anionic PNP Pincer Ligands. Angew. Chem., Int. Ed. 2016, 55, 14291-14295.

(12) Sekiguchi, Y.; Arashiba, K.; Tanaka, H.; Eizawa, A.; Nakajima, K.; Yoshizawa, K.; Nishibayashi, Y. Catalytic Reduction of Molecular Dinitrogen to Ammonia and Hydrazine Using Vanadium Complexes. Angew. Chem., Int. Ed. 2018, 57, 9064-9068.

(13) Doyle, L. R.; Wooles, A. J.; Jenkins, L. C.; Tuna, F.; McInnes, E. J. L.; Liddle, S. T. Catalytic Dinitrogen Reduction to Ammonia at a Triamidoamine-Titanium Complex. Angew. Chem., Int. Ed. 2018, 57, 6314-6318.

(14) Fajardo, J., Jr.; Peters, J. C. Catalytic Nitrogen-to-Ammonia Conversion by Osmium and Ruthenium Complexes. J. Am. Chem. Soc. 2017, $139,16105-16108$.

(15) Meng, F.; Kuriyama, S.; Tanaka, H.; Egi, A.; Yoshizawa, K.; Nishibayashi, Y. Ammonia Formation Catalyzed by Dinitrogen-Bridged Dirhenium Complex Bearing PNP-Pincer Ligands under Mild Reaction Conditions. Angew. Chem., Int. Ed. 2021, 60, 13906-13912.

(16) Kendall, A. J.; Mock, M. T. Dinitrogen Activation and Functionalization with Chromium. Eur. J. Inorg. Chem. 2020, 2020, 1358-1375.

(17) Shiina, K. Reductive Silylation of Molecular Nitrogen via Fixation to Tris(trialkylsilyl)amine. J. Am. Chem. Soc. 1972, 94, 9266-9267.

(18) (a) Zhang, Q.-F.; Chim, J. L. C.; Lai, W.; Wong, W.-T.; Leung, W.-H. Bridged Dinitrogen Complexes of Iron and Chromium Porphyrins. Inorg. Chem. 2001, 40, 2470-2471. (b) Monillas, W. H.; Yap, G. P. A.; MacAdams, L. A.; Theopold, K. H. Binding and Activation of Small Molecules by Three-Coordinate Cr(I). J. Am. Chem. Soc. 2007, 129, 8090-8091. (c) Berben, L. A.; Kozimor, S. A. Inorg. Chem. 2008, 47, 4639. (d) Hoffert, W. A.; Rappé, A. K.; Shores, M. P. Unusual Electronic Effects Imparted by Bridging Dinitrogen: an Experimental and Theoretical Investigation. Inorg. Chem. 2010, 49, 9497-9507. (e) Mock, M. T.; Chen, S.; Rousseau, R.; O’Hagan, M. J.; Dougherty, W. G.; Kassel, W. S.; DuBois, D. L.; Bullock, R. M. A Rare Terminal Dinitrogen Complex of Chromium. Chem. Commun. 2011, 47, 12212-12214. (f) Monillas, W. H.; Yap, G. P. A.; Theopold K. H. Reactivity of a Low-Valent Chromium Dinitrogen Complex. Inorg. Chim. Acta 2011, 369, 103-119. (g) Akturk, E. S.; Yap, G. P. A.; Theopold, K. H. Mechanism-Based Design of Labile Precursors for Chromium(i) Chemistry. Chem. Commun. 2015, 51, 15402-15405. (h) Li, J.; Yin, J.; Wang, G.-X.; Yin, Z.-B.; Zhang, W.-X.; Xi, Z. Synthesis and Reactivity of Asymmetric Cr(i) Dinitrogen Complexes Supported by Cyclopentadienyl-phosphine Ligands. Chem. Commun. 2019, 55, 9641-9544.

(19) (a) Kendall, A. J.; Johnson, S. I.; Bullock, R. M.; Mock, M. T. Catalytic Silylation of $\mathrm{N}_{2}$ and Synthesis of $\mathrm{NH}_{3}$ and $\mathrm{N}_{2} \mathrm{H}_{4}$ by Net Hydrogen Atom Transfer Reactions Using a Chromium $\mathrm{P}_{4}$ Macrocycle. J. Am. Chem. Soc. 2018, 140, 2528-2536. (b) Yin, J.; Li, J.; Wang, G.-X.; Yin, Z.-B.;
Zhang, W.-X.; Xi, Z. Dinitrogen Functionalization Affording Chromium Hydrazido Complex. J. Am. Chem. Soc. 2019, 141, 4241-4247. (c) Eaton, M. C.; Knight, B. J.; Catalano, V. J.; Murray, L. J. Evaluating Metal Ion Identity on Catalytic Silylation of Dinitrogen Using a Series of Trimetallic Complexes. Eur. J. Inorg. Chem. 2020, 2020, 1519-1524.

(20) (a) Egbert, J. D.; O’Hagan, M.; Wiedner, E. S.; Bullock, R. M.; Piro, N. A.; Kassel, W. S.; Mock, M. T. Putting Chromium on the Map for $\mathrm{N}_{2}$ Reduction: Production of Hydrazine and Ammonia. A Study of cis$\mathrm{M}\left(\mathrm{N}_{2}\right)_{2}(\mathrm{M}=\mathrm{Cr}, \mathrm{Mo}, \mathrm{W})$ bis(diphosphine) complexes. Chem. Commun. 2016, 52, 9343-9346. (b) Sobota, P.; Jezowska-Trzebiatowska, B. Fixation of Dinitrogen and Acetylene by the System $\mathrm{CrCl}_{2}-\mathrm{Mg}$. Isolation and Properties of Chromium Complexes with Fixed $\mathrm{N}_{2}$ and $\mathrm{C}_{2} \mathrm{H}_{2}$. J. Organomet. Chem. 1977, 131, 341-345. (c) Vidyaratne, I.; Scott, J.; Gambarotta, S.; Budzelaar, P. H. M. Dinitrogen Activation, Partial Reduction, and Formation of Coordinated Imide Promoted by a Chromium Diiminepyridine Complex. Inorg. Chem. 2007, 46, 7040-7049. (d) Mock, M. T.; Chen, S.; O’Hagan, M.; Rousseau, R.; Dougherty, W. G.; Kassel, W. S.; Bullock, R. M. Dinitrogen Reduction by a Chromium(0) Complex Supported by a 16-Membered Phosphorus Macrocycle. J. Am. Chem. Soc. 2013, 135, 11493-11496. (e) Mock, M. T.; Pierpont, A. W.; Egbert, J. D.; O’Hagan, M.; Chen, S.; Bullock, R. M.; Dougherty, W. G.; Kassel, W. S.; Rousseau, R. Protonation Studies of a Mono-Dinitrogen Complex of Chromium Supported by a 12-Membered Phosphorus Macrocycle Containing Pendant Amines. Inorg. Chem. 2015, 54, 4827-4839.

(21) Yang, L.; Powell, D. R.; Houser, R. P. Structural variation in copper(i) complexes with pyridylmethylamide ligands: structural analysis with a new four-coordinate geometry index, $\tau 4$. Dalton Trans. 2007, 955-964.

(22) Bain, G. A.; Berry, J. F. Diamagnetic Corrections and Pascal's Constants, J. Chem. Educ. 2008, 85, 532.

(23) (a) Bottomley, L. A.; Neely, F. L. The nitrogen atom transfer reactivity of nitridomanganese(V) porphyrins with chromium(III) porphyrins. J. Am. Chem. Soc. 1989, 111, 5955-5957. (b) Neely, F. L.; Bottomley, L. A. The preparation of nitridomanganese and nitridochromium macrocyclic complexes by complete intermetal nitrogen atom transfer from nitridomanganese octaethylporphyrin. Inorg. Chim. Acta 1992, 192, 147-149. (c) Neely, F. L.; Bottomley, L. A. Inter-Metal Nitrogen Atom Transfer Reactions between Nitridochromium(V) and Chromium(III) Porphyrins. Inorg. Chem. 1997, 36, 5432-5434. (d) Bottomley, L. A.; Neely, F. L. Stereoelectronic aspects of inter-metal nitrogen atom transfer reactions between Nitridomanganese(V) and chromium(III) porphyrins. Inorg. Chem. 1997, 36, 5435-5439. (e) Bendix, J. $\left[\mathrm{Cr}(\mathrm{N}) \mathrm{Cl}_{4}\right]^{2-}:$ A simple nitrido complex synthesized by nitrogen-atom transfer. J. Am. Chem. Soc. 2003, 125, 13348-13349. (f) Birk, T.; Bendix, J. Atom transfer as a preparative tool in coordination chemistry. Synthesis and characterization of $\mathrm{Cr}(\mathrm{V})$ nitrido complexes of bidentate ligands. Inorg. Chem. 2003, 42, 7608-7615. (g) Bendix, J.; Birk, T. Weyhermüller, T. Molecular and electronic structure of chromium(v) nitrido complexes with azide and isothiocyanate ligands. Dalton. Trans. 2005, 2737-2749. (h) Hedegaard, E. D.; Schau-Magnussen, M.; Bendix, [Cr(N)(acac) 2$]$ : A simple chromium nitride complex and its reactivity towards late transition metals. J. Inorg. Chem. Commun. 2011, 14, 719721.

(24) Arashiba, K.; Tanaka, H.; Yoshizawa, K.; Nishibayashi, Y. Cycling between Molybdenum - Dinitrogen and - Nitride Complexes to Support the Reaction Pathway for Catalytic Formation of Ammonia from Dinitrogen. Chem. - Eur. J., 2020, 26, 13383-13389. 


$$
\begin{aligned}
& \mathrm{N}_{2}+\mathrm{KC}_{8}+\left[\mathrm{PCy}_{3} \mathrm{H}\right] \mathrm{BF}_{4} \underset{-78{ }^{\circ} \mathrm{C}}{\stackrel{\text { cat. } \mathrm{Cr}}{\longrightarrow}} \mathrm{NH}_{3}+\mathrm{N}_{2} \mathrm{H}_{4}
\end{aligned}
$$

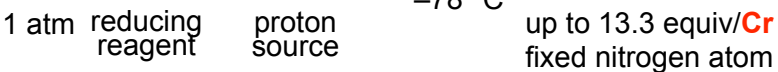

$$
\begin{aligned}
& \text { cat. } \mathrm{Cr}
\end{aligned}
$$

